\title{
ARTICLE
}

\section{External Dose Conversion Coefficients to Assess the Radiological Impact of an Environmental Radiation on Aquatic and Terrestrial Animals}

\author{
Dong-Kwon KEUM*, In JUN, Kwang-Muk LIM, Yong-Ho CHOI \\ Korea Atomic Energy Research Institute \\ 150 Deokjindong, Yuseonggu, Daejeon, 305-353 Korea
}

\begin{abstract}
To assess the radiological impact of environmental radiation, a set of external dose conversion coefficients for 7 Korean reference aquatic and terrestrial animals (rat, roe-deer, frog, snake, Chinese minnow, bee and earthworm) are presented for 25 radionuclides $\left({ }^{3} \mathrm{H},{ }^{7} \mathrm{Be},{ }^{14} \mathrm{C},{ }^{40} \mathrm{~K},{ }^{51} \mathrm{Cr},{ }^{54} \mathrm{Mn},{ }^{59} \mathrm{Fe},{ }^{58} \mathrm{Co},{ }^{60} \mathrm{Co},{ }^{65} \mathrm{Zn},{ }^{90} \mathrm{Sr},{ }^{95} \mathrm{Zr},{ }^{95} \mathrm{Nb},{ }^{99} \mathrm{Tc},{ }^{106} \mathrm{Ru},{ }^{129} \mathrm{I}\right.$, ${ }^{131} \mathrm{I},{ }^{136} \mathrm{Cs},{ }^{137} \mathrm{Cs},{ }^{140} \mathrm{Ba},{ }^{140} \mathrm{La},{ }^{144} \mathrm{Ce},{ }^{238} \mathrm{U},{ }^{239} \mathrm{Pu}$, and $\left.{ }^{240} \mathrm{Pu}\right)$. The external dose conversion coefficients have been calculated by the uniform isotropic model for aquatic animals, and by the Monte Carlo method, which can simulate a photon transport in environmental media with different densities, for terrestrial animals. In the modeling all the target animals are defined as a simple 3D elliptical shape. To specify the external radiation source it is assumed that aquatic animals are fully immersed in infinite and uniformly contaminated water, and the on-soil animals are living on the surface of a horizontally infinite contaminated soil, and the in-soil organisms are living at the center of a horizontally infinite and uniformly contaminated soil to a depth of $50 \mathrm{~cm}$.
\end{abstract}

\section{KEYWORDS: external dose conversion coefficient, non-human species, uniform isotropic model, Monte Carlo simulation}

\section{Introduction}

Traditionally, radiation protection has been focused on a radiation exposure of human beings. In the international radiation protection community, one of the recent key issues is to establish the methodology for assessing the radiological impact of an ionizing radiation on non-human species for an environmental protection. ${ }^{1-2)}$ To assess the radiological impact to non-human species dose conversion coefficients are essential. This paper describes the methodology to calculate the external dose conversion coefficient for non-human species and presents calculated external dose conversion coefficients of 25 radionuclides for 7 domestic reference aquatic and terrestrial animals.

\section{Methods}

The uniform isotropic model has been applied to calculate the external dose conversion coefficients for aquatic animals, while the Monte Carlo simulation for a photon transport has been applied for terrestrial animals.

\section{Uniform isotropic models for aquatic animals}

The uniform isotropic model has been often used to calculate the external dose conversion coefficient for aquatic animals living in water of which the density is almost the same as that of the organisms' body. ${ }^{3-4)}$ The model is expressed by

$D_{e x t}=\sum_{v}\left(\sum_{i} E_{i} y_{i}\left(1-\phi\left(E_{i}\right)\right)+\int N_{\beta}(E) E(1-\phi(E)) d E\right)(1)$

* Corresponding Author, Phone: 82428682058 ; Fax: 8242868 8606, E-mail: dkkeum@kaeri.re.kr where $D_{\text {ext }}\left(\mu \mathrm{Gyd}^{-1}\right.$ per $\left.\mathrm{Bqkg}^{-1}\right)$ is the external dose conversion coefficients; $\nu$ denotes a radiation type $(\alpha, \beta, \gamma)$; $E_{i}(\mathrm{MeV})$ and $y_{i}\left(\right.$ decay $\left.^{-1}\right)$ are energy and yield of the discrete energy radiations per decay of the radionuclide; $N_{\beta}(E)$ $\left(\right.$ decay $\left.^{-1} \mathrm{MeV}^{-1}\right)$ is the continuous energy spectrum of $\beta$ particles; $\phi(E)$ is the absorbed energy fraction, which is defined as the fraction of energy emitted by a decaying radionuclide that is absorbed within the organism.

To calculate the external dose conversion coefficient, $E, y$, $\varphi$, and $N_{\beta}$ should be known. The transformation data of the radionuclides, $E$ and $y$, were referenced from the ICRP $38^{5)}$, and the $\beta$-energy spectrum $N_{\beta}$ was extracted from the DexRax32 code of the Oak Ridge National Laboratories, USA. $\left.{ }^{6}\right)$ The absorbed energy fraction $\varphi$ was determined by the empirical equation associated with the Monte Carlo simulation, which was developed by Ulanovsky and Pröhl. ${ }^{4)}$

\section{Monte Carlo simulation for a photon transport}

Terrestrial animals live in heterogeneous system in materials and densities. To consider the heterogeneities, radiation transport in a terrestrial medium is usually simulated by the Monte Carlo technique. The external dose conversion coefficients for specific source activity for terrestrial animals can be simply calculated by

$$
D_{\text {ext }}=\sum_{i} A_{\text {ext }}\left(E_{i}\right) y_{i}
$$

where $A_{\text {ext }}\left(E_{i}\right)$ ( $\left.\mu \mathrm{Gy} . \mathrm{kg}\right)$ is the absorbed dose for a specified photon energy $E_{i}(\mathrm{MeV}) ; y_{i}\left(\right.$ decay $\left.^{-1}\right)$ is yield of a photon per decay of the radionuclide.

To calculate the $A_{e x t}\left(E_{i}\right)$ values for a specified energy, the Monte Carlo simulation for a photon transport in environmental media was separately performed for in-soil and on-soil animals with respective different assumptions. 
(1) In-soil animals

Animals that live in soil are fully exposed by the surrounding contaminated soil. To estimate the external exposure for the in-soil animals, such as earthworms, snakes, frogs, and rats in this work, the transport of a photon in the soil was calculated using MCNP code ${ }^{7)}$ with the following assumptions (Fig. 1)

(a) Transport mode: photon

(b) Shape of organisms: ellipsoid (size is in Table 1)

(c) Initial energy: 7 energies in the range from $0.01 \mathrm{MeV}$ to $3 \mathrm{MeV}$

(d) Radiation source: uniformly contaminated soil up to a depth of $50 \mathrm{~cm}$ with an effectively infinite horizontal dimension $(100 \mathrm{~cm} \times 200 \mathrm{~cm} \times 50 \mathrm{~cm})$. The transport distance of photon in soil is not greater than $10 \mathrm{~cm}$.

(e) Target organism is located at a depth of $25 \mathrm{~cm}$

(f) Snake, frog and rat are surrounded by the air of $0.5 \mathrm{~cm}$ thickness, but earthworm is not surrounded by air.
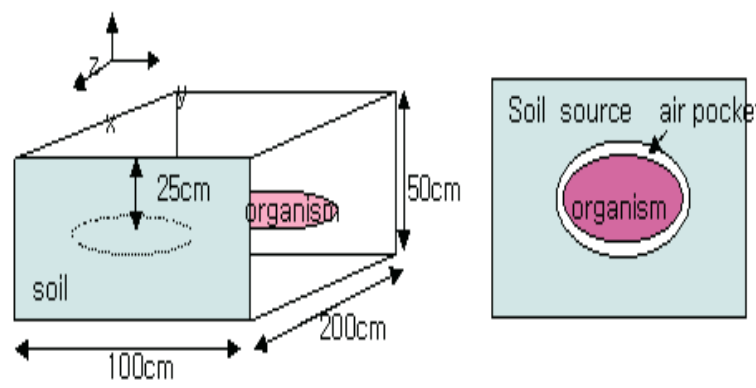

Fig.1 MCNP model geometry for in-soil animals

(2) On-soil animals

Animals that live on soil, such as earthworms, bees, snakes, frogs, rats, and roe deer in this work, are exposed to radiation emitted from the contaminated soil surface. Because a photon can transport long distance in air, a very large medium around a target organism should be considered to obtain an acceptable result. However, this method is impractical due to a very long computation time. Taranenko et al. ${ }^{8)}$ proposed an alternative method to resolve the computation problem in the direct Monte Carlo simulation for a photon transport for the on-soil animals. They applied the two-step approach to calculate the absorbed dose as follows.

$$
A_{\text {ext }}\left(E_{i}\right)=K\left(h, E_{i}\right) r\left(h, E_{i}\right) m_{s}
$$

where $K\left(h, E_{i}\right)(\mu \mathrm{Gy})$ is the air kerma at the height $(h)$ of the target on ground; $r\left(h, E_{i}\right)$ (unitless) is the ratio of the bodyaveraged dose for the target to air kerma for the air of the same size with the target at a height $h ; m(\mathrm{~kg})$ is the mass of contaminated soil source.

To calculate $K$ and $r$ at the height of an on-soil animal for a specified initial energy, the Monte Carlo simulation was performed with the following assumptions.

(a) Transport mode : photon

(b) Model universe: vertical cylinder (Figs 2\&3)
- radius and height $(3 \mathrm{~km})$ for air-kerma simulation;

- radius and height $(20 \mathrm{~m})$ for $r$ value simulation

(c) Air target layer thickness: $1 \mathrm{~cm}$

(d) Soil is contaminated up to $10 \mathrm{~cm}$ of total depth of $5 \mathrm{~m}$

(e) Initial energy:

- 22 energies in the range from $0.05 \mathrm{MeV}$ to $5 \mathrm{MeV}$ for air-kerma simulation

- 5 energies in the range from $0.05 \mathrm{MeV}$ to $3 \mathrm{MeV}$ for $r$ value simulation

(f) Height of target is corresponding to the half of the minor axis length of an ellipsoid (c/2). (Table 1)

(g) Material composition of organism, soil, and air were taken from the literature. ${ }^{8)}$

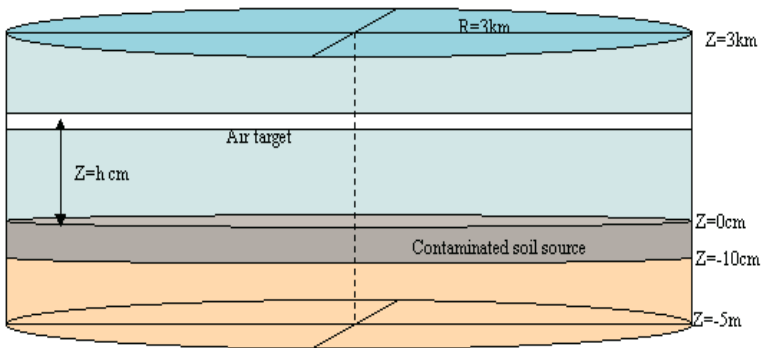

Fig.2 MCNP model geometry for air kerma simulation
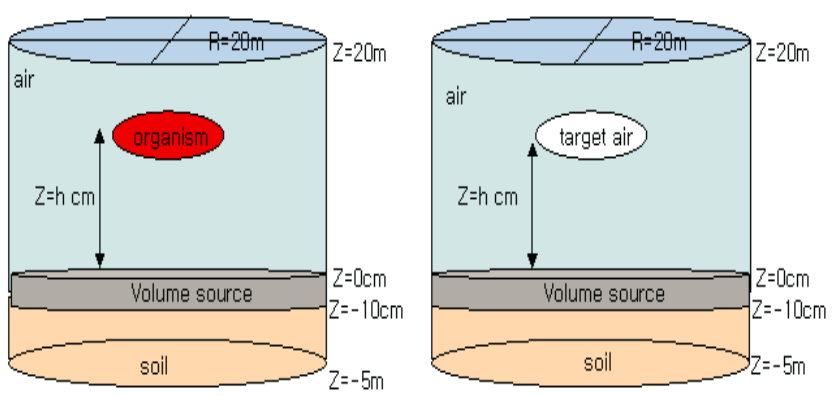

Fig.3 MCNP model geometry for $r$ value simulation

\section{Results and Discussion}

\section{Korean reference animals}

Table 1 shows the domestic reference organisms that were used in the calculation of the external dose conversion coefficient. The reference animals were selected based on the ICRP new recommendation ${ }^{2)}$ and EIR (Environmental Impact Report) for the Gyeongju ILLW repository, Korea. The size of the selected organisms was taken from the "Endemic Species of Korea"9). The shape of all the organisms was assumed to be ellipsoid. For an ellipsoid, $a$, $b$, and $c$ is respectively the lengths of the major, 1st minor and 2 nd minor axis

\section{Radionuclides}

For the above selected domestic organisms, external dose conversion coefficients were calculated for 25 radionuclides $\left({ }^{3} \mathrm{H},{ }^{7} \mathrm{Be},{ }^{14} \mathrm{C},{ }^{40} \mathrm{~K},{ }^{51} \mathrm{Cr},{ }^{54} \mathrm{Mn},{ }^{59} \mathrm{Fe},{ }^{58} \mathrm{Co}\right.$, ${ }^{60} \mathrm{Co},{ }^{65} \mathrm{Zn},{ }^{90} \mathrm{Sr},{ }^{95} \mathrm{Zr},{ }^{95} \mathrm{Nb},{ }^{99} \mathrm{Tc},{ }^{106} \mathrm{Ru},{ }^{129} \mathrm{I},{ }^{131} \mathrm{I},{ }^{136} \mathrm{Cs},{ }^{137} \mathrm{Cs}$, $\left.{ }^{140} \mathrm{Ba},{ }^{140} \mathrm{La},{ }^{144} \mathrm{Ce},{ }^{238} \mathrm{U},{ }^{239} \mathrm{Pu},{ }^{240} \mathrm{Pu}\right)$. The radionuclides 
came from the environmental radiation monitoring program of Gyeongju ILLW repository. In all the calculations, the progenies with half lives less than 10 days of each radionuclide were incorporated in the external dose conversion coefficient calculation of its parent radionuclide.

Table 1. Geometry of the reference animals

\begin{tabular}{llccc}
\hline \multirow{2}{*}{ Organism } & \multirow{2}{*}{\begin{tabular}{l} 
Ecosystem \\
\cline { 3 - 5 }
\end{tabular}} & \multicolumn{3}{c}{ Size $(\mathrm{cm})$} \\
\hline Rat & $\mathrm{I}, \mathrm{O}$ & $b$ & $c$ \\
Roe deer & $\mathrm{O}$ & 10 & 3 & 2.5 \\
Frog & $\mathrm{W}, \mathrm{I}, \mathrm{O}$ & 105 & 50 & 50 \\
Snake & $\mathrm{I}, \mathrm{O}$ & 3.2 & 3 & 2 \\
Minnow & $\mathrm{W}$ & 85 & 1 & 1 \\
Bee & $\mathrm{O}$ & 8 & 3 & 1 \\
Earthworm & $\mathrm{I}, \mathrm{O}$ & 1.8 & 0.5 & 0.5 \\
\hline
\end{tabular}

* I: in-soil, O: on-soil, $\mathrm{W}$ : water

\section{External Dose Conversion Coefficients, $D_{\text {ext }}$}

Absorbed energy fraction, $\phi$, for aquatic animals in Eq. 1 was in the range from an order of $10^{-5}$ for high energy of photon and small size organisms to unity for low energy and large organisms. The absorbed fraction for the electron was larger than that for the photon because the transport distance in a material of a photon is considerably larger than that of electron at the same energy strength.

The external absorbed doses, $A(E)$ ( $\mu \mathrm{Gy} . \mathrm{kg}$ ), in Eq. 2 were in the range of $10^{-11}$ to $10^{-8}$ for in-soil animals, and from $10^{-14}$ to $10^{-9}$ for on-soil animals, and it increased with the strength of the energy. But there was no difference in the value between animals considered when $E>0.03 \mathrm{MeV}$, except for the roe deer of on-soil animals. For the roe deer, the absorbed dose appeared to be less than that of the other smaller animals owing to the pronounced self-shielding effect of the large animal.
Figs. 4 to 6 show the external dose conversion coefficients for the aquatic, in-soil, and on-soil animals, respectively. The values are in the range from 0 to 0.035 $(\mu \mathrm{Gy} / \mathrm{d}$ per $\mathrm{Bq} / \mathrm{kg})$, according to radionuclide and animal. For all the animals considered, the external dose conversion coefficients appear higher for $\gamma$ emitting radionuclides such as ${ }^{140} \mathrm{Ba},{ }^{60} \mathrm{Co},{ }^{134} \mathrm{Cs},{ }^{59} \mathrm{Fe}$, and ${ }^{140} \mathrm{La}$, while the values are extremely small (less than $10^{-5}$ ) for radionuclides that emit a low energy radiation such as ${ }^{14} \mathrm{C},{ }^{3} \mathrm{H},{ }^{129} \mathrm{I},{ }^{90} \mathrm{Sr},{ }^{239} \mathrm{Pu},{ }^{240} \mathrm{Pu}$, ${ }^{99} \mathrm{Tc}$, and ${ }^{238} \mathrm{U}$. Low energy radiation emitting from such radionuclides is not strong enough to penetrate effectively into the tissue of the target organism. For the same reason, the radionuclides become a very important contributor in the internal dose rate.

For the same radionuclide, the external dose conversion coefficients for aquatic and in-soil animals are almost the same, but they are larger by about a factor of 3 than that for the on-soil animals. This is because the aquatic and in-soil animals are fully immersed in the infinite source, while the on-soil animals are exposed to a semi-infinite source according to the model assumptions.

In general, the external exposure rate decreases with the increasing the size of target organism due to the pronounced self-shielding effect of a large target organism. It can be seen that the external dose conversion coefficients of roe deer, which is the largest of on-soil animals considered, is lower than that for the smaller animals (Fig. 6). For in-soil animals, there is no difference in the external dose conversion coefficient between animals, except for the earthworm that shows a little larger external dose conversion coefficient (Fig. 5). This result was attributed to the fact that the earthworm was assumed to be directly contacted with the contaminated soil without considering the air pocket at outside of the target organism in the calculation of the external dose conversion coefficient.

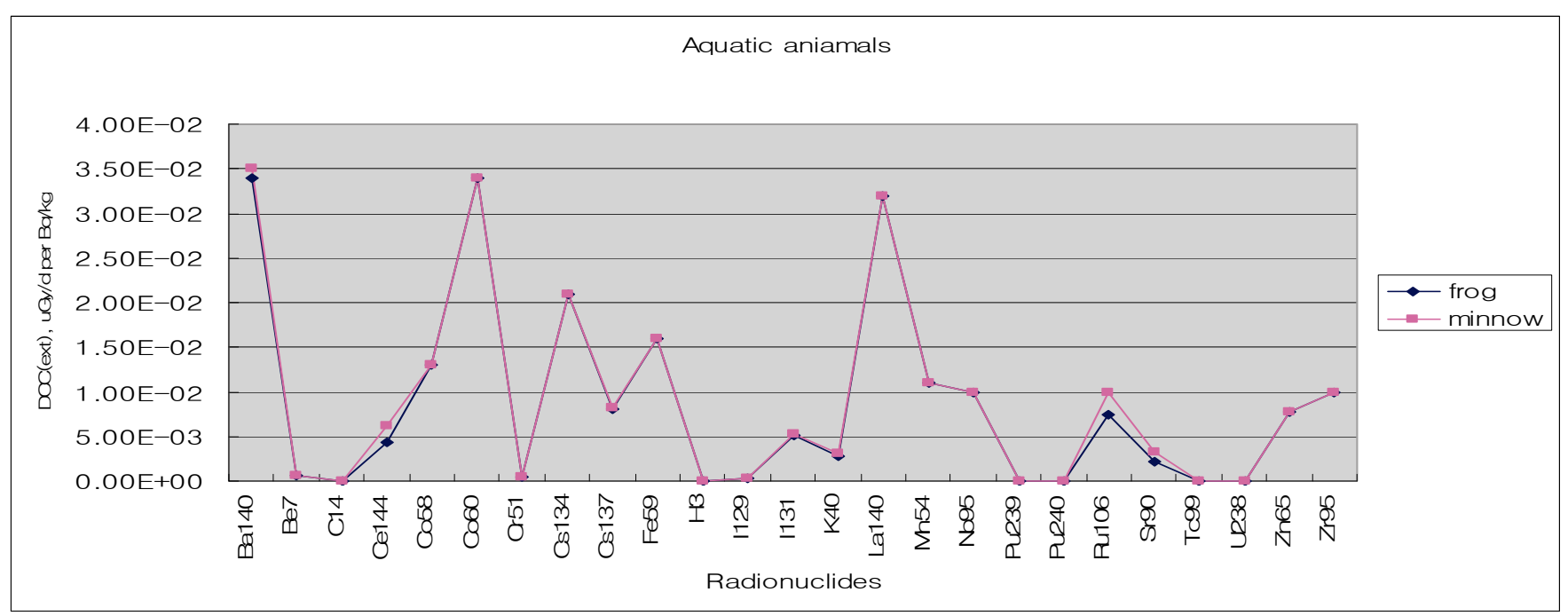

Fig. 4 External dose conversion coefficients for frog and Chinese minnow 


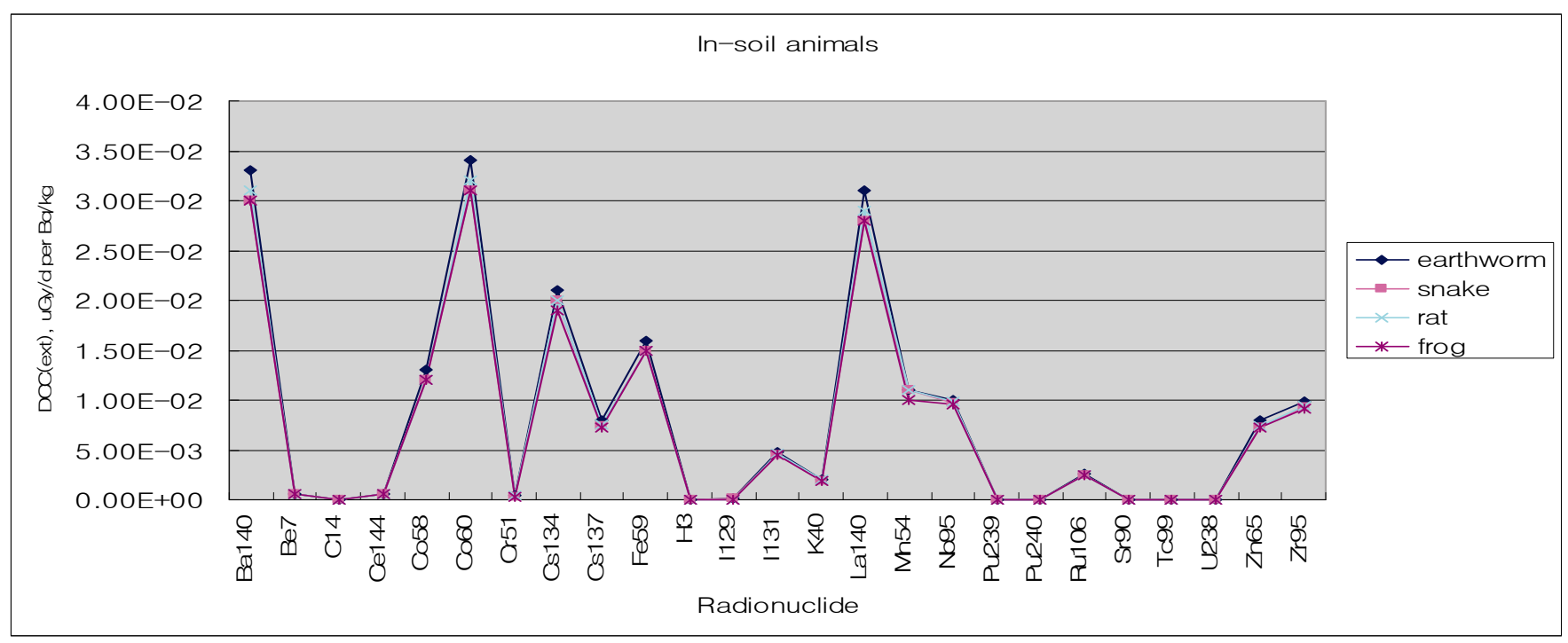

Fig. 5 External dose conversion coefficients for in-soil animals

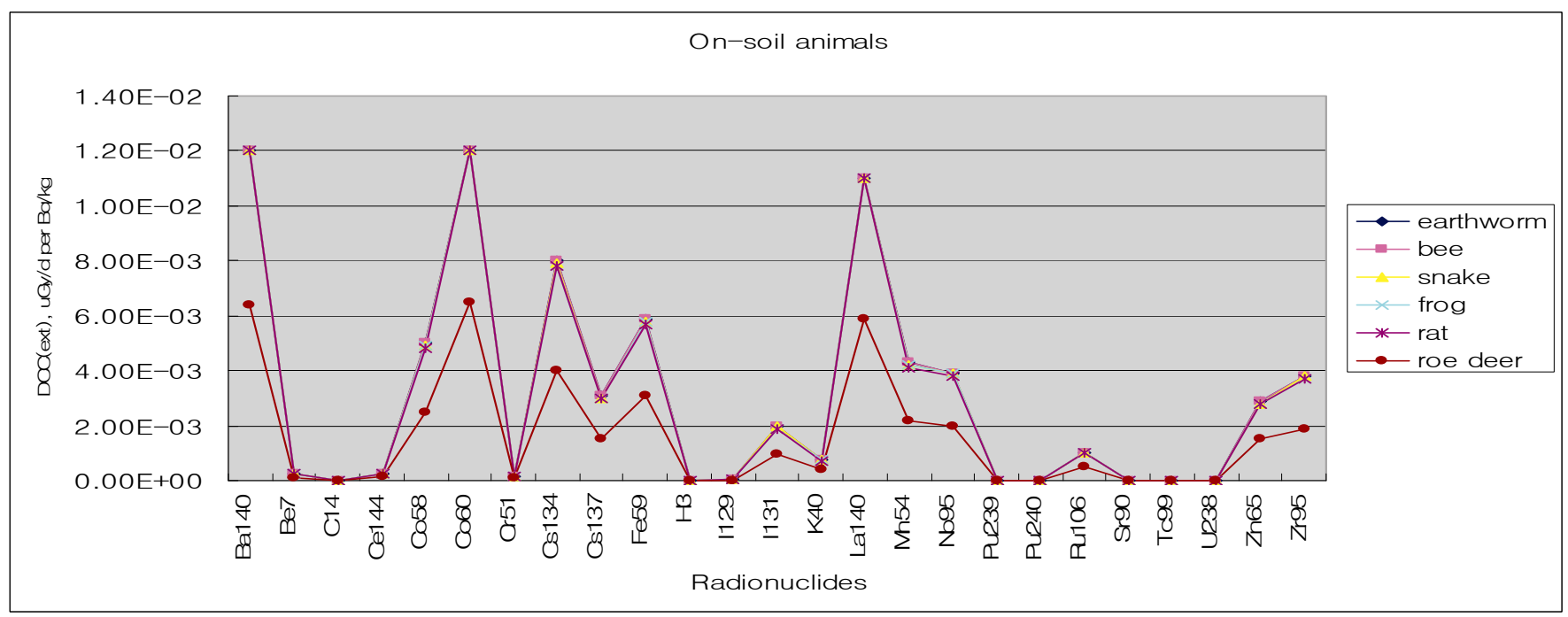

Fig. 6 External dose conversion coefficients for on-soil animals

\section{Acknowledgement}

This work has been financially supported by the Ministry of Education, Science and Technology, Korea

\section{References}

1) International Atomic Energy Agency, Protection of the environment from the effect of Ionizing radiation, Proceedings of an International Conference, Stockholm, Sweden, October 6-10, (2003).

2) International Commission on Radiological Protection, The 2007 Recommendations of the ICRP, Publication 103, Pergamon Press, Oxford and New York (2008).

3) B.J. Vives, S.R. Jones, J.M. Gomez-Ros, "A method for calculation of dose per unit concentration values for aquatic biota," J. Radiol. Prot., 24, A13 (2004).

4) A. Ulanovsky, G. Pröhl, "A practical method for assessment of dose conversion coefficients for aquatic biota," Radiat. Environ. Biophys., 45, 203 (2006).
5) ICRP, Radionuclide transformations: energy and intensity of emissions, Annals of the ICRP, Publication 38, Pergamon Press, Oxford, New York and Frankfrut(1983).

6) K.F. Eckerman, R.J. Westfall, J.C. Ryman, M. Cristy, "Availability of nuclear decay data in electronic form, including beta spectra not previously published," Health Phys, 67[4], 338 (1994).

7) J.F. Briesmeister (ed), "MCNP- A general Monte Carlo Nparticle transport code: Version 4B", LA-12625-M, version 4B, UC705, University of California, issued March, (1997).

8) V. Taranenko, G. Pröhl, J.M. Comez-Ros, “Absorbed dose Rate conversion coefficients for reference terrestrial biota for external and internal exposures," J. Radiol. Prot., 24, A35 (2004).

9) Hwangyeongbu, Endemic Species of Korea, Ministry of Environment of Korea, (2005), [in Korean]. 